Journal of Mechanics in Medicine and Biology

Vol. 7, No. 3 (2007) 265-274

\title{
THE EFFECT OF LOAD CARRIAGE AMONG PRIMARY SCHOOL BOYS: A PRELIMINARY STUDY
}

H. N. SHASMIN, N. A. ABU OSMAN*, R. RAZALI, J. USMAN and W. A. B. WAN ABAS

Motion Analysis Laboratory, Department of Biomedical Engineering

Faculty of Engineering, University of Malaya

Kuala Lumpur 50603, Malaysia

\section{Introduction}

Schoolchildren lugging bags packed with books are a perennial problem. In Malaysia, the Ministry of Education has introduced the periodic table and serial textbooks to reduce the weight of school backpacks. The changes were made when many teachers and parents voiced their concern about the load of school bags, especially in early 2002. However, heavy school bags remain a yearly problem as some subjects, especially the language classes, require five or six exercise books (not counting the textbooks). The bags can weigh up to $10 \mathrm{~kg}$, about half of the student's body weight. Rolling backpacks have been recommended by United Kingdom professionals, but these bring their own array of challenges such as difficult manipulation on stairs, storage within schools, and passage through crowded hallways and buses.1 Besides, most primary school students in this country prefer to use double-strapped and rigid backpacks.

The main idea of this project is to analyze the load carriage effect among students.

The effect is viewed on children's gait and posture from full biomechanics analysis. At the end of this study, a safe load limit for children is suggested. In other countries, many researches about load carriage among students have been done. The majority of biomechanical studies with children's backpacks have examined the effect of different loads on three main parameters: trunk forward lean, craniovertebral angle, and gait.2 The studies suggested that the suitable load carry by the students is $10 \%-15 \%$ of body weight; when a load more than that is carried, the student will probably experience physical changes such as bad posture and shoulder depression.3

\section{Methods}

\subsection{Questionnaires}


The methodology of this study can be divided into two main steps. The first step was to find suitable schoolchildren to be the subjects; the second step was the experiment on biomechanical analysis. To begin with, a proposal paper was sent to the school to obtain permission and cooperation for the survey. The survey forms were distributed to 77 students from Primary 3 to Primary 5 (9-11 years old). The questionnaires were important to review the types of school bags that the students were currently using and the schoolchildren's subjective perceptions of their backpack loads. After students' weight and height were measured, several were selected to participate in the experiment.

\subsection{Subjects}

Seven boys with a mean age of $10.28 \pm 0.72$ years were selected from a local primary school to participate in this study. The boys best represented their age group in terms of their body mass index (BMI). The mean body mass and height of the subjects were $28.7 \pm 0.73 \mathrm{~kg}$ and $134.7 \pm 5.30 \mathrm{~cm}$, respectively. Prior to participation in this study, the whole procedure was explained orally to the parents and they were asked to read and sign a written informed consent.

All experiments were conducted at the Motion Analysis Laboratory, Department of Biomedical Engineering, Faculty of Engineering, University of Malaya, Kuala Lumpur, Malaysia. During the experiments, subjects were asked to walk on a floor with four different load conditions: without a bag ( $0 \%$ of body weight) and with a school bag of $10 \%, 15 \%$, and $20 \%$ of body weight. The most popular school bag a two-strap, rigid backpack - was employed in the experiment.

\subsection{Experimental procedure}

The children wore dark uniforms with socks and shoes. After consents were obtained from the subjects' parents, anthropometric measurements of the subjects (including body height and weight) were taken and reflective markers were attached to their body segments. These reflective markers represented specific bone landmarks such as ankle, knee, and shoulders.

Afterward, the children were required to walk in a straight line along a distance of $5 \mathrm{~m}$ at their own comfortable speed on a floor which was equipped with Kistler_Force Platform Type 9281C to detect their ground reaction forces (GRFs). To avoid any disturbance from the attached markers at the legs, the children 
were allowed to walk several times at the testing area to perform their best gait before recording. The stance phase of the subjects was filmed by four sets of $50-\mathrm{Hz}$ shuttered closed-circuit television (CCTV) cameras. Before the experiment started, a calibration procedure was conducted using a 17-point calibration frame and the global transformation frame (GTF). The GTF marked the $x-, y$-, and $z$-axes. This procedure was important for digitizing purposes. The reflective markers that were recorded into the videotapes were digitized on a motion analysis system by using a human body model. Full biomechanical analysis was then done using Peak Motus_ 7.2.4 software. A Butterworth low-pass filter from the software was used to smooth the data for anatomical landmarks and GRFs.

\subsection{Measurement}

One stance phase theoretically includes the foot strike, opposite foot strike, foot flat, midstance, heel off, and toe off.4 Stance phase is defined as the period during foot contact with the ground.5 For kinetic measurement, analysis was done on three components of GRF: vertical GRF, medial-lateral GRF, and anterior-posterior GRF. For kinematics measurement, analysis was done on joint angles such as hip and knee flexion/extension as well as on changes in trunk angle when the subject carried more load in his backpack. The GRF is the propulsive force in walking. According to previous studies, $6-9$ all components of the GRF are proportional to the load increment. The stance duration was also measured in this study.

\subsection{Statistics}

One-way analysis of variance (ANOVA) from SPSS_version 12.0 software was used to test for significant differences. If the calculation was significant, a univariate oneway ANOVA was performed on each different load condition to determine those which possessed significant variance. A statistical significance level of 0.05 was set.

\section{Results}

\subsection{Questionnaires}

The questionnaires distributed to the school consisted of three sections: demographic information, school bag usage, and students' perceptions of their backpacks. The questionnaires were answered by 77 school boys. In the section on school 
bag usage, about $95 \%$ of children used a standard two-strap, rigid backpack; of these, about $80 \%$ reported using both straps on their shoulders. From the questionnaires, $31 \%$ of the students said that their backpacks were uncomfortable and heavy. The level of satisfaction of carrying a backpack differed depending on the children's age. Further investigation was done in this study to observe whether these children faced any biomechanical problems when carrying the backpacks.

\subsection{Ground reaction forces (GRFs)}

The results of this study showed that in vertical GRF, when the load was increased the force also increased. This condition occurred in all of the subjects. The GRF components of boy 3 had experimental errors in this study, as no results could be obtained from all of the trials at $10 \%$ and $20 \%$ of his load conditions; this happened as the boy did not perform his gait on the force platform. During the experiment, two platforms were set to sense gait forces for normal footsteps of children, but the step of boy 3 was wider than the normal range of children's footsteps (Fig. 1). However, results from boy 3 were still analyzed in the kinematics parameter. The shapes of vertical GRF from the other boys were almost similar to each other in every load condition, but the forces varied according to the subject mass and percentage load of body weight carried by the boys. These force values are shown in Table 1. Figure 2 shows an example of vertical GRF from a subject. From the Fig. 1.

Full text is available at :

http://www.worldscientific.com/doi/abs/10.1142/S0219519407002285 